\title{
From Age Diversity to Embedded Ageing: Exploring and Addressing Aged
}

\section{Assumptions in Organizational Practices}

\author{
Sophie Hales and Kathleen Riach
}

The growing recognition that ageing is central to any management and policy agenda across the world has signalled moves both at a legislative level via discrimination law and through organizational initiatives to welcome workers of all ages. However, there are still questions over the efficacy of these developments in ensuring that individuals are afforded meaningful, secure employment that draws on their individual, specific and accumulated skills and competencies throughout their working lives. One reason for this has been the ongoing challenge of transforming attitudes surrounding how organizational stakeholders behave, think and relate to those viewed as being at a particular stage in their lives. A growing evidence base of studies that suggest unfavourable perceptions surrounding older workers still exist and are often intimately intertwined to other social categories including gender (Moore, 2009; Irni, 2009) and socio-economic status or class (Zanoni, 2011; Riach and Cutcher, 2014). Similarly, at a structural level there is a growing concern that as individuals grow older they face increasing challenges in advancing in or re-entering the labour market (Hirsch et al., 2000; Chan and Stevens, 2001). At the same time, 'younger' workers may be viewed negatively and those at the beginning of their careers may also face difficulty in finding work that is developmental, meaningful and holds promising career opportunities for advancement (McDowell, 2011). However, a key intermediary between these two levels of inequality is ‘Organization'. This not only considers age-specific policies or practices, but considers ageing at work as simultaneously experienced and understood through a range of norms and assumptions about what constitutes 'work'. In this sense, a contextual understanding of ageing is needed which considers how insidious beliefs surrounding age, stage and ability may 
manifest within the bureaucratic and often mundane practices and policies that form part of the day to day structuring and cultural context of organizational life.

In this chapter we show how these life course positions and cultural dimensions of organization must be considered as simultaneously experienced in and co-constructed alongside the broader sociomaterialities of work. To do so, we situate our discussion in a broadly sociological account on ageing that has been particularly influential within Organization Studies as a sub discipline of business and management research. Although this is an approach that embraces a plurality of different perspectives, its theoretical sympathies lie in understanding ageing as a contextually embedded phenomenon configured by various cultural, social, political and historical circuits that are used to shape people's meaning of age and ageing. This moves a conceptualisation of ageing away from being something that is objectively measured and encountered, to a phenomenon that is experienced, negotiated and accomplished. Therefore, resituating ageing as an active force that both shapes and is shaped by organizational practices must be accepted if initiatives surrounding age diversity and positive age management are to have significant impact. In particular, we need to move away from age as being either primarily chronologically determined or implicitly 'attached' to an individual or group of employees. Instead, there is a need for them to consider how larger narratives surrounding ageing not only influence individual perceptions but constitute part of a broader landscape where organizational bodies, practices and sites intermingle to constitute what ageing at work means. To do so, we begin by exploring the two common lenses that influence the way we think about, and subsequently shape, organization age management practices. We then develop recent commentaries surrounding new materialisms as a means of introducing the concept of 'embedded ageing'. We argue that considering the interstices through which we come to understand both ageing at work and work practices themselves may be one way of articulating 
the penetration of taken-for-granted aged paradigms in organizational practices. By means of exemplifying the explanatory purchase of embedded ageing, we close with organizational examples relevant to the organization of ageing, suggesting how an embedded ageing approach may serve to reorientate the way we consider ageing in an organizational context.

\section{From Age and Employment to the Organization of Ageing}

Age and Employment studies (AES) is an interdisciplinary field drawing from research traditions including social gerontology, psychology, sociology, and social policy. Scholars are drawn together by a broad concern with how age is perceived, experienced and managed within workplaces and the labour market more generally. Until recently, this has focussed empirically on exploring 'older worker experience', leaving other disciplinary silos, such as youth studies, to focus on other specific age cohorts. In many ways, this is to the detriment of the discipline, both theoretically, in terms of the ways we think about age as primarily focussed on individuals or groups (rather than organizations), and practically, where we become concerned with practices that assume chronological identification is our primary classifier. This has meant that for the large part, age and employment studies locates 'age' as derived from the individuals, rather than from the messages or cultural puzzle pieces we draw on in organizations to make sense of what age is at a broader epistemological level.

To move age on from something attached to an individual to a phenomenon intimately related to larger dynamics within and surrounding working life, it is therefore important to shift attention away from age as a classifier, category or identifier. Instead, we need to turn to how ageing as a process is not simply something that 'happens' to an individual within a particular setting, but rather is actively negotiated through, experienced in and constituted alongside 
socio-cultural settings themselves. This helps to reorientate our focus on what may influence age relations through breaking away from assumptions or truth claims about what is 'old', for example. While the focus has been on age of the individual rather than broader ageing dynamics, the potential for age and employment studies to draw from its interdisciplinary heritage to uncover these dimensions is already realised in some ways, although rarely talked about in such explicit theoretical terms. For example, the field has benefited from debates surrounding the structural or political economies that result in age-related inequality throughout the labour market (e.g. Walker, 1981; Grady, 2013). Within this work, a move away from individual age toward interrogating how structures inform and organize ageing helps to emphasise, for example 'the role of social policies in opening up or closing down opportunities for older people' (Walker, 2005: 816).

However, exploring ageing as an organizationally constituted phenomenon is by no means a one size fits all approach. Following interdisciplinary traditions in AES, there are a variety of ways we can understand ageing that each take different views on the role and importance of the body, culture and structure. To begin exploring these positions in more depth, it is useful to identify two contrasting perspectives surrounding ageing that have been formative in the field of AES.

\section{Ageing as biological}

The first dominant assumption within AES is that ageing is closely correlated with a biologically-determined life span. This is what we might term a 'biomedical foundation'- that is, a predominant concern with the biological processes associated with both growing older or particular stages of life. Specifically, physical processes of inevitable biological decline are classified and require increasing medical intervention through biologised ascription. In many 
ways this intimate association between age and the body is unsurprising given that traditionally, chronological age has been used to define and classify clinical practices and structures that have played a formative role in early studies of age at work. In particular, theories derived from clinical gerontological studies were often used in early studies of older workers, even though those being researched were considerably younger than those who were traditionally the focus of gerontology. This influence was also seen in studies choosing to draw on frameworks of understanding derived from developmental psychology where assumptions were made surrounding chronological age and cognitive or physical changes (e.g. Rhodes, 1983).

In this sense, the body is at the centre of ageing debates, situated as an entity that can be 'entered, studied and tampered with in order to be repaired' (Koch and Webb, 1996: 957). Of course, this concern with engaging in medicalised body practices that will positively influence ageing has been enduring since the enlightenment when ageing moved from a religious to scientific 'problem. For example, former US president Benjamin Franklin charged science as having a cure for all ailments, including old age, while others engaged in a variety of experiments, such as $19^{\text {th }}$ century endocrinologist Brown-Sequard who self-injected a concoction of animal blood, juice and semen as a strategy of rejuvenation (Cole, 2002; Haber, 2004). However, what is of note is that the dominance of a biomedical understanding of age has had a significant influence on the way that ageing is used to pathologise, demarcate and inevitably marginalize people - a trend that can also be seen in research exploring ageing and work. For example, studies continue to begin from psychological and medical evidence of functional decline as a basis of differentiation between different age cohorts (e.g. Ilmarinen, 2001; Popkin et al., 2008). However, at a conceptual level, this strengthens the idea that age is an indicator which is (i) primarily used as an individual identifier; and (ii) a stable effect that can be measured or managed in some way. Together, this results in an implication that 'age' is a classifier that 
holds some degree of homogeneity across individuals, and can subsequently be used as both a control variable in studies and quantified within managerial interventions.

As age expectancy increases, and the chronological difference between an 'older worker' and an 'older person' becomes even more significant, the immediate transplanting of ideas surrounding ageing medically and ageing at work has altered, although the continued influence of medicalised accounts of ageing can be seen as policy and practice mirror the changing approaches to ageing in the natural sciences. Specifically, the move from a deficiency and decline assumption as assumed in early clinical studies of ageing has been superseded by a return to questioning the inevitability of unidirectional decline and the role of both environment and individual action of slowing down or even reversing the ageing process. As Martin and Gillen (2013) suggest, this may be closer to the original intentions of one of gerontology's founding fathers, Metchnikoff, who first identified the need to consider older age beyond a solely biological context back in 1903. However, the translation of broader social and contextual considerations has most recently been dominated by the term 'successful ageing' (Rowe and Kahn, 1997). Emerging from functionalist theories surrounding ideas of continued engagement and roles ascribed to particular life stages, such as activity theory (Lemon et al., 1972), successful ageing has sought to challenge the idea of 'natural' decline and instead focus on how individuals have the possibility (and some would say the responsibility) to behave and act in particular ways that will maintain health and wellbeing as they grow older (Katz and Calasanti, 2014).

In this sense, successful ageing, or its corollary, 'productive' or 'active' ageing (terms popularised in policy accounts of growing older productively in the sense of active employment and little reliance on social systems), can be seen as a renaissance of biomedical dominance in 
studies of ageing. This allow managers to articulate ageing as primarily something that happens to the body and can be mitigated against, as opposed to being done by the body or even part of what makes a body, a living body. For example, we see recommendations and strategies that can help the older worker to 'offset' possible performance-related declines as one ages (Abraham and Hanssen, 1995; Baltes and Baltes, 1990; Robson et al., 2008). In many instances, such approaches focus on individual dispositions or competencies, inadvertently negating the importance of other factors that may cause inequality. At the same time, the biomedical view of age has significant implications for the creation of labour markets created to cater for the maintenance and bodywork of those who have 'succumbed' to ageing, notably the aged care sector.

These foundational understandings of ageing as biological may not be explicit in age management policies, but are nonetheless foundational in how we think about age diversity. First, age diversity is based on the premise of being able to identify 'the diverse', often through looks or physical appearance. In doing so, this identification leads to the assumption that those who share some characteristic of diversity may be subject to the same experiences of opportunities in an organization. Second, age management often uses markers (such as 'ages 50-65') to group together individuals, once again reinforcing the notion that some 'truth' may be garnered through chronology. While there may be some overlapping of experience due to shared experiences across a cohort, there is a danger in taking a proxy, such as chronology, as fully explaining the complexity of individual experience within an organizational setting. Finally, the dominance of successful ageing in the rise of later life health initiatives that form diversity campaigns can be seen as part of a broader critique of organizational wellbeing agendas as negating institutional responsibility for occupationally-derived health issues such as work intensification and stress, all of which may accumulate over the life course (Dale and 
Burrell, 2014). Such debates, whilst rooted in an assumption of the ageing process as driven by biology, introduce ideas surrounding individual responsibility, as well as economic rationale about who may be best to invest in commercially.

\section{Ageing as socio-culturally constructed}

The second lens through which to understand age and organization draws on poststructuralist accounts of reality, where there is a concern not with a 'substance' of age in any material sense, but rather how particular ideals or narrative serve to constitute and reproduce our understanding of age or age-related matters. In other words, to understand what ageing is, we cannot turn to the individual or the body for answers or facts, but instead must look at how particular messages and norms surrounding what ageing means are constituted, reproduced and transformed in a variety of social arenas such as work, home and the media. This position asks us not only to explore particular norms surrounding ageing at work, but identify and question what (sociallyconstructed) assumptions those norms are built upon. For example ageing events often use a fixed idea of objective time as sanctified in the Gregorian calendar, and both Bytheway (1995) and Fineman (2011) explore the cultural significance of birthdays. In focussing on ageing as socially constructed, we are encouraged not to think about a birthday as a fixed point in the objective passing of time, but rather an important symbolic event that is organised in ways that encourage individuals to draw particular meanings. As Fineman (2011: 25) suggests in his discussion of birthday cards: 'They 'bottle' age [...] oblique and not-so-oblique jokes sit alongside cards that tease, provoke, mock, shock, sexualize, debunk, or flatter'. In the same way, such time-orientated events may be recognised within an organization, or even created within organizational practices. Celebrations of years of service or eligibility for certain workrelated benefits are based on a social consensus of the fixed measurement of time that are both 
sanctified in how society understands the passing of time, and recognised by organizational stakeholders as a legitimate threshold for differentiating between employees.

The past 20 years has seen a growing interest in viewing ageing in organizations through this lens, particularly within discursive accounts of ageing (Ainsworth and Hardy, 2008; Riach, 2009; Spedale et al., 2014). Discursive accounts of ageing at work focus on the identification effect of particular ideological repertoires that circulate organizational arenas. For example, they may focus on ways that older workers are marginalized through the presences of aged subject positions that suggest individuals who look or act in an age-typed way are more or less appropriate for particular types of work. Ainsworth and Hardy (2008) suggest that 'older workers' are both co-opted and precluded within discourses of enterprise while Pritchard and Whiting (2014) suggest that the presentation of generational comparisons in itself legitimizes organizational differentiations through age. Elsewhere, Trethewey (2001) has shown how professional women have to negotiate a discourse of decline through strategies of managing looks and behaviour. The policies of practices organizations adopt at an institutional level may also reproduce aged biases. For example, Zanoni (2011) demonstrated how older workers were negatively positioned within a factory's 'lean' processes. Alongside other commonly ascribed diversity categories, such as 'disabled' and 'women', older workers were positioned in a way that was intimately connected to justifications surrounding the organizational policies such as outsourcing, to ensure profitability, suggesting that diversity dynamics 'are related to specific institutional contexts in which they are embedded' (Zanoni, 2011: 121). Similarly, Riach and Kelly (2013: 8) show how practices surrounding regeneration, restructuring and technological change in organizations may coalesce with older worker exit strategies since 'the image that is synonymous with an older worker may embody what organizations are continually trying to 
avoid: the old, worn-out, out-of-date, unfit parts of an organization that need to be replaced or hidden in some way'.

Elsewhere, other scholars have focussed on the social construction of ageing as influencing larger trends and assumptions that influence organizations and labour market policy more generally. For example, Katz (2000) draws on a Foucauldian notion of governmentality to suggest that age is subject to a range of 'technologies' - techniques through which individuals come to recognise themselves or others as legitimate or socially recognisable. These invariably close down a plurality of how we can express our ageing experience since they limit ways in which, for example, 'older workers' or 'younger workers' are expected to behave. Foucault's ideas have proven similarly influential within age and employment studies where scholars such as Moulaert and Biggs (2013) have drawn on ideas surrounding power relations to show how the idealization of active ageing described previously mean that ageing 'successfully' is now both a choice any older person can make, and a failure of the individual not to subscribe to such ideals.

A reorientation of ageing as a social construction has also provided useful ways of critiquing biomedical views of ageing discussed above. Understanding that many views of ageing may appear to focus on the body as a biological fact or entity but are actually culturally constructed in a particular way to produce truth claims about ageing allows researchers to reintroduce the importance of power and control in terms of who creates and controls biomedical messages surrounding ageing. In particular, both the successful ageing and anti-ageing movement have been subject to critique for advocating modification that requires the 'right' investment of professional lifestyle and consumer choices by the individual. In this sense, ageing - or the prevention of the effects of ageing - becomes an aspirational means through which 
discrimination and labour market disadvantage can be avoided if one is prepared to personally invest in its prevention. For example, keeping skills and competencies 'up to date' or ensuring the working body can 'endure' the onslaught of long hours or a highly stressful job becomes an individual responsibility and necessary investment in today's economy (see Riach and Kelly, 2013). Similarly, who is identified as an 'older worker' may differ across occupational settings and professions depending on the organizational cultures or norms (Fineman, 2011).

Within this position then, we see the possibility of moving from exploring ageing as a process that operates in and around a 'neutral' container of an organization towards a more processual understanding of the organization of ageing. In other words, ageing itself, along with other unspoken ideals and assumptions, can be seen as a central principle in how we come to understand organization life and the policies and practices which come to constitute work. This requires us to think of organizations not as vessels in which ageing happens, but rather as entities made and constituted by the constructed ideas and messages surrounding ageing that circulate society. If we agree that 'organization is the way it runs through the process of organizing' (Weick, 1969: 91), ageing is seen as one component used to make sense of, and subsequently influence how organizations are created.

This has significant consequences for how we view age diversity practices and how they operate within organizations. For example, focus turns to how assumptions surrounding age diversity as a concept is constituted in organizations that in turn implements practice. We may also question how policies allow people to differentiate between legitimate (such as pension age) and illegitimate (such as discrimination) differentiation based on an age category (Riach, 2009). This can also help us to understand how the language and terminology we use to discuss ageing and growing older in a workplace not only impacts on how employees think about age, 
but themselves have been created through drawing on norms and assumptions about how people grow older. Such a lens is therefore important for reminding practitioners and organizations that policies may be both a reaction to, and a reproduction of, negative ascriptions to particular groups of workers.

However, at the same time, a focus on the social construction of ageing sees the mutual constitution of ageing and organization as occurring at the level of language and culture. Emphasis on how we think and talk about ageing may therefore inadvertently neglect how the ageing body itself is an integral part of working life beyond being a 'symbol' of looking old or young that can be read through particular cultural scripts. At the same time, we can see that ageing, while seen as subject to a number of constructed ideals, is still understood as something that happens to us, rather than being ascribed a more dynamic or 'lived' quality. In exploring an alternative approach to ageing, we must consider how ageing itself is experienced and transformed within organizational realms inter alia.

\section{Towards an Embedded Ageing}

To recap, emphasising ageing as both an issue for management consideration and a phenomenon that shapes and is understood through organizational life is one of the key challenges facing today's workplaces. We have begun to see a consideration of the former in the form of both diversity initiatives often targeting particular cohorts of workers, or the emergence of broader 'age management' strategies, as discussed elsewhere in the book. However, it may be that we also need to simultaneously consider the way age and ageing is integral to parts of the organization that are often not the focus of equality or diversity practices, ensuring that the context and individual experience are not relegated. To try and articulate the possibilities for exploring this further within a relational approach that takes into account how 
we experience ageing as a dynamic embodied process in organizations, we now introduce what we term here an 'embedded ageing' approach.

'Embedded ageing' is one lens through which to explore the relationship between age-related assumptions, lived experience, organizational norms, expectations and practices. Ageing in organization is thus understood as focussing on the relationalities between actors (people or other phenomena), knowledges (how we come to be orientated or make meaning of our worlds) and sites (the contexts in which we are embedded). In doing so we seek to unearth and reflect on and subsequently appreciate how an individual's positionality within this realm may produce particular aged effects.

While such an approach is growing in popularity within disciplines including, media (Parikka, 2012) and cultural studies (Alaimo, 2010), it is still to gain traction within studies of organizational life in general, and studies of ageing in particular. Embedded ageing as a concept is informed by a range of theoretical positions including actor-network theory, performativity, phenomenology and new materialism, this broad set of positions focuses on ageing as experienced through the relationships and interactions between bodies, sites, objects and ideologies and has begun to make inroads into studies of organizational life through highlighting both the positionality and durability of particular ideas or assumptions (such as those surrounding older workers) as situated in particular places and times, latterly, how this is intertwined with particular ethical imperatives surrounding change or responsibility (Scott and Orlikowski, 2012). For example, in this sphere, we understand ageing as a material manifestation of embodied temporality, not a priori separate to the social or cultural production of regimes surrounding 'youth' or 'old'. These systems of relations between people, things, processes and objects, often termed 'assemblages' or 'entanglements', highlight how ageing is 
at once embedded in the context in which it is experienced, and punctuating the way we come to understand different aspects of the (working) world.

In many ways this changes the ontology of ageing beyond something that happens to us either through biology, or through understanding various cultural scripts. At the same time, in following the logic of recent accounts of the sociomateriality of work (e.g. Orlikowski and Scott, 2008), we can still recognise the extent to which particular practices of ageing - notably through embodied experience - intersect with organizational life and larger socio-cultural ideas surrounding growing up and older, caring structures and retirement. As Carlile et al (2013: 2, original emphasis) suggest 'activities in organizations are not merely situated in the ideational realm by deeply implicate sociomaterial practices through which they are enacted...through the use of objects, the training and use of the body and engagement in certain practices'. Attempts to articulate growing older within this approach therefore begin by understanding the experience of ageing at work as an inherently relational process. This process is invariably manifested in the simultaneous intertwining of cultural production and material experience and recognises ageing as simultaneously 'felt' in particular embodied experiences and interpreted through an exchanging, colluding and colliding of socio-cultural scripts.

While accounts of age and work rarely refer to their sociomaterial understandings of ageing, increasingly we see a consideration of both bodily experience and cultural apparatus of ageing being simultaneously considered. For example, a number of age and employment studies drawing on a concept of generation also provide a space for considering how our embodied positionality in a particular time and space may overlap or differentiate with others. While some work has found explanatory purchase in generation as short-hand for 'cohort' and a differential point of comparison between different age groups (e.g. Benson and Brown, 2011), 
others engage with a sociologically-informed concept of positionality of the self within particular landscapes or experiences that may shape outlook, beliefs or interpretations on the world of work.

Elsewhere, we can see the beginnings of a more radical recognition of positioning the ageing body as an active primae facie basis for experience and knowledge. This means that the aged body becomes both the way we come to understand and experience the world and the site through which various socio-cultural ideas and narratives are inscribed. For example, Riach and Cutcher's (2014: 782) study of ageing in the financial services shows how 'temporal, spatial and cultural contexts that the traders lived in and through do not simply surround their bodies: they are etched onto them'. In this sense, ageing is always a situated phenomenon that cannot be extracted from either organizational context or an individual's location within the life course. Focussing on embedded ageing therefore holds distinct possibilities for how we come to understand ageing. On the one hand, it provides one way of considering a context-rich account of ageing at work that must take into account that we come to 'know' ageing through work and in turn, work is constituted through our understanding and experience of ageing. At the same time, it provides possibilities for recognising that ageing is a temporal experience on the body and that we may differ from others in relation to both our situated experience, and our accumulated understanding, of the world. To further develop these insights in terms of their implications for ageing and employment and age diversity more specifically, we now articulate the key principles that underline the concept of 'embedded' ageing'.

First, embedded ageing does not negate the pervasiveness of cultural messages or ideas surrounding ages, nor deny that we experience bodily changes as we move in and through time. The body is not seen as a reactive vessel in a biomedical sense, nor conceptualised as something 
that can be reduced to the sum of discourse or signification. Instead, our bodies are reciprocal agents with other living and non-livings things that come to simultaneously engage with and rebound into the world. This suggests that ageing is not simply an individually located experience or sociocultural phenomenon, but experienced through our situated presence in particular organizational sites and trajectories. This allows us to consider employees as holding particular attributes and characteristics that are the result of both interactions and accumulative skills they have experienced over their own personalised trajectories, and capabilities inflected in the historical and cultural remnants of the organizational site in which they are currently situated. This may be understood through Ingold's (2000) concept of 'dwelling', as a way of highlighting how knowledges are created through both our orientation to the world and our interaction with other people, objects and environments. At the same time, we need to be mindful that within workplaces individuals can often come to understand and subsequently make decisions about their own and others' positionality and accumulation through particular organizational and social narratives or cultural scripts. Such scripts may inadvertently negate individual attributes or dispositions. Embedded ageing provides a way of articulating the importance of age 'mattering' through taking account of the embodied experience of ageing within particular contexts without problematizing or denigrating particular groups or individuals.

Second, within an embedded ageing approach, we forefront the relationality of all the different aspects that serve to constitute organizational life. It is in the enmeshment of ideas surrounding ageing bodies, the sites in which they are located in terms of particular spaces at particular points in time, and organizational regimes that both react to and interact with a number of external environmental factors that we begin to understand how age organizes work patterns, practices and structures, similar to the way that studies have explored gendering in 
organizations (e.g. Acker, 1990); what we might somewhat clumsily call 'ageanizing'. In other words, we appreciate how age is both an organizing principle and logic that structures the way we think about all aspects of work and society, not simply those we think of as explicitly or immediately related to age and ageing. Key to this is understanding the potential for not just individuals, but other entities to enact or affect a world or work that is in a constant state of rematerializing. While this may feel like an almost overwhelming task to begin to consider, it does allow us to consider how different aspects of an organization come together to tell a story about ageing, exploring the points of similarity and difference that emerge.

Finally, embedded ageing captures the dynamism of ageing and organization as mutually constituted and created. In doing so, it helps to introduce previously unrelated elements of organizational life and ageing. For example, we may consider how recruitment practices and strategies and promotion opportunities are underlined by similar or different temporal landscapes in which we understand our experience of growing older. However, to view this as simply 'carried through' or reproduce discourse fails to show how, once those recruitment policies are committed to paper, they may in themselves enact ideas which they were not intentionally or originally related to surrounding who is desirable, ideal, or wanted within the organization. This may in turn be used to produce different workforce populations or inform promotion or organizational cultural activities. In providing a lens in which we can begin to explore these ideas, embedded ageing allows a broader consideration of how practices or context that were developed with no explicit reference to ageing may be helping or hindering the potential of a workforce through inadvertent or hidden aged biases.

\section{Exploring Embedded Ageing in Organizational Practice}


The embedded ageing approach as introduced above may require us to reimagine ageing as we currently conceive of it within an organizational setting, which invariably presents us with challenges in terms of how it translates into practice. To reduce embedded ageing to an identification of negative perceptions may negate the importance of the situated body in how we all come to understand and explore ageing at work. On the other hand, to only consider the body may result in a reduction to an individualised focus on managing the biomedical problem of ageing. Therefore, in this final section, we will present some possibilities for how an embedded ageing approach may begin to help us think through age diversity in a workplace setting in a way that takes into account the mutual constitution of ageing and organization.

First, embedded ageing calls into account practices that may appear on the surface to be ageneutral and subjects them to a mode of 'age auditing'. Age auditing is a means of resituating ageing vis a vis practices and contexts that on first sight, may preclude any explicit mention or even immediate association with ageing but are nonetheless part of the world that invariably influences how we come to 'ageanize'. In practice, this may involve an actual auditing process, such as multiple-stakeholder question sessions, or via the use of an age-embedded audit tool to help identify and rate. This may then be subsequently used as a basis for strategies to challenge aged-affects. Below is an abbreviated example of an auditing tool that may be used within specific departments as a means of identifying age-embedded aspects of work practices and procedures. This particular tool is based on a 5 point scale of unmet ( 0 points), partly met ( 2 points) and met (4 points), with a higher overall score suggesting more 'age aware' practice (maximum of 40 points).

Table 1: 'Embedded Age' Audit Tool

Department/Unit: 


\begin{tabular}{|c|c|c|}
\hline \multicolumn{3}{|c|}{ Name of Auditor: } \\
\hline \multicolumn{3}{|c|}{ Date: } \\
\hline & Areas of Practice & Rating \\
\hline \multicolumn{3}{|c|}{ DESIGNING PRACTICES AND PROCEDURES (P\&P) } \\
\hline 1 & $\begin{array}{l}\text { Is there clarity surrounding what previous experience end users may } \\
\text { require during design } \mathrm{P} \& \mathrm{P} \text { ? }\end{array}$ & \\
\hline 2 & $\begin{array}{l}\text { Are systems or practices developed by a multi-generational team with } \\
\text { different disciplinary backgrounds? }\end{array}$ & \\
\hline 3 & $\begin{array}{l}\text { Is there a consideration of different end users prior knowledge during } \\
\text { P\&P design? }\end{array}$ & \\
\hline 4 & $\begin{array}{l}\text { Is there flexibility in the P\&P design to take into account differing levels } \\
\text { of familiarity with key elements? }\end{array}$ & \\
\hline \multicolumn{3}{|c|}{ IMPLEMENTING P\&P } \\
\hline 5 & Does implementation recognise the benefits of previous systems? & \\
\hline 6 & Is take-up assessed and possible reasons behind this trend discussed? & \\
\hline 7 & $\begin{array}{l}\text { Do estimated time allocations take into account diverse approaches to } \\
\text { learning and knowledge accumulation? }\end{array}$ & \\
\hline \multicolumn{3}{|c|}{ COMMUNICATION } \\
\hline 8 & $\begin{array}{l}\text { Are communication tools free from jargon, social media language and } \\
\text { acronyms? }\end{array}$ & \\
\hline 9 & $\begin{array}{l}\text { Are image stocks used in communication representative of a wide } \\
\text { demographic? }\end{array}$ & \\
\hline 10 & $\begin{array}{l}\text { Do feedback mechanism provide an opportunity to assess perceptions of } \\
\text { efficacy based on demographics? }\end{array}$ & \\
\hline
\end{tabular}


In contrast to diversity which often focuses on specific practices, age auditing invites a consideration of ageing where it has previously not been considered. However, as Lorbiecki and Jack (2000) argue in their broader discussion of diversity, such an approach must focus on ageing as an issue that affects all, rather than forming a consensus around what 'younger' or 'older' employees need, as such an oversimplification of similarities and differences may inadvertently encourage essentialist accounts of difference. Slipping into damaging dualisms thus requires a language that takes into account trajectories, rather than concepts of time-served, for example.

To explore this further we can take two examples of organization practice where commonly attributed stereotypes have forged a connection between 'older workers' and workplace activity: Change Management and IT. While we of course question the intent behind ascribing these attributes or ideas to a large heterogeneous group, such as 'older workers', likewise it is unhelpful to simply dismiss stereotypes as having no explanatory purchase when their prevalence and continued circulation signals some kind of currency for a number of people. Instead we may understand these as two areas of organizational life where ageanizing is empirically visible.

Change management or, more specifically, how organizations plan, design and execute change within their organizations has been one sphere where aged biases come to the surface. Research suggests that employers not only view older workers as less adaptable to change but possibly actively resistant of change (Loretto and White, 2006; Parry and Tyson, 2009). However, change fatigue may also be more likely to be experienced by those who have been in an organization longer and have therefore been through a larger number of changes. Similarly, older workers have been commonly associated with hesitance or difficulty with IT systems. 
For example, Van Dalen et al (2009) highlighted how older workers were often perceived as having lower motivations surrounding IT training while Malul (2009) follows a modernisation thesis in suggesting that compared to those aged 18-40, older workers (those aged over 50) are significantly negatively affected by technological change - in this sense older workers caution of new IT developments is well founded. This may of course be related to perceptions surrounding resistance to change, since IT is one of the main areas where constant updating or upgrading is a common occurrence within the workplace. However, IT is also an example of a practice that has not only integrated into professional (and social) practice, but had correspondingly transformed how people think and behave.

To take change first, embedded ageing reminds us that change itself is a relational management practice: it relies on a situated relationship between a (flawed) past to a (better) future. Similarly, we assume that as individuals' age, there is some continuity of stream which can somehow be used as a proxy for judgement surrounding competency or skill. Change in this context brings forth particular assemblages, including aged ideologies or assumptions. These ideas are ensconced within the dynamics and disruption of organizational change itself that may have consequences for individuals as they move through the life course. Embedded ageing thus calls for a reconsideration of not just the people involved in change, but how organizational change itself may be disrupted in a way that sets up new modes of practice that create intensified structures and systems of working. For example, the temporal proximity of information, often fed asynchronously (such as two people writing an email reply at the same time) and the need to assimilate information together as well as the location where the information is ingested (such as on mobile devices at any time of the day) does not simply alter the experience of work, but transforms work in a way that may be impossible to have imagined 30 years ago. Such changes are part of the new organization ontologies that create 'systems that enable people to 
filter, control, and manage their relationships with the spaces and people around them' (De Souza e Silva and Frith, 2012: 5). At the same time, the consequences for not filtering, controlling and managing relationships in a way that is advocated by an organization may have significant consequences for an individual, either in terms of intensification, burnout or performance monitoring.

The second possibility where embedded ageing may help to identify or reconfigure aged biases is within IT. Drawing on an embedded ageing approach allows us to simultaneously recognise the importance of the situated experience of particular employees across space and time while at the same time articulate how socio-cultural scripts are played out in the material constitution of technology. In other words, the technological systems that are developed within organizations must be seen as part of the intra-activity of organizational life recognising that 'distinct entities, agencies, events do not precede, but rather emerge from/through their intraaction’ (Barad, 2010: 267).

Situating seismic change in IT practices and possibilities must therefore be considered as a phenomenon created through individuals' practices comingling with it. For example, it is not the particular computer programme that constitutes the 'IT initiative', but rather the creation of 'the IT' as created through the fusion of individual and computerised action. Rather than simply thinking about how an employee uses IT, it is the experience of this convergence that is taken as 'IT'. In relation to ageing, this allows us to depart from the user (or the IT) as a passive recipient or receptacle that is to be used or can use in a homogenous or consistent way. Instead, this may take into account how an individual's orientation to IT is subject to their particular orientation in a particular space, time and context. We can understand employees as 'dwelling' (Ingold, 2000) in particular positions vis a vis IT. Dwelling suggests that our embodied position 
in time and space influences our own particular ways of knowing that subsequently orientate us in particular ways to certain objects or ideas such as computers or electronic systems and practices. From this situated positionality, we not only come to understand the world a particular way, but are afforded or disavowed certain possibilities that translate into our actions and behaviours. For example, if we have always known of using touch screens, then the way we practically navigate our way around any new piece of equipment with a screen may be distinct (not necessarily better or worse) from another person who has a different mode of orientation grounded in non-touch screen products. However, it is when this orientation is translated through sociocultural attributions of value or judgment based on notions of 'familiarity' or 'competency’ attributed to dwelling positions that aged biases may emerge.

This sentiment is echoed by McMullin et al. (2007) who suggest that professional IT workers themselves may express contrasting 'generational affinities' as a result of the contrasting roles IT has throughout their life. However, building on McMullin et al.'s (2007) idea of generational affinities may also result in aged bias being built into the actual constitution of IT delivery within organizations. For example, if this degree of similarity not only influences how one views technology but how one interacts or learns with it, then who develops and delivers IT training, and how various manuals and programmes are structured may have a significant impact on who the training 'speaks' to. In other words, embedded ageing may help to expose how assumptions surrounding positionality and orientation are intersticed into IT communication or development in ways that may become imbued with aged bias.

\section{Conclusion: Beware of the 'Age Traps'}

In this chapter we have suggested how moving away from a focus on age as a category, or ageing as either biologically or culturally understood may present new opportunities for linking 
together organization bodies, materialities and sites. On the one hand, as Thomas et al. (2014: 1570) suggest, 'age works as a master signifier' in terms of holding explanatory currency surrounding norms, expectations and values on account of how old one looks, behaves or is chronologically marked. However, from our discussion of the paradigmatic fault lines upon which ageing rests, ageing within an organizational realm must consider the intermingling of different bodies, practices and contexts in order to fully understand how ageing is experienced, understood and subsequently articulated. While still in its relative infancy, the concept of 'embedded ageing' may begin to help us explore how age diversity is part of the interwoven relationalities in which we come to understand and live in the experience of ageing at work. Ageing as a mode of sociomaterial configuration is inherent to how organizations themselves cohere. Since there is no single symbolic or material entity surrounding age or ageing that operates in and of itself, age diversity practices must therefore be mindful of the various 'age traps' that exist in organizations. These age traps may include policies or practices that are imbued with perceptions or ideas about ageing that inadvertently marginalize or favour where one should be and what one should be doing at a particular point within the working life course. To this extent, moving from viewing age as attached to a fixed category or cohort that can, must or should be managed towards a consideration of how ageing effects and experiences are embedded and subsequently manifest in practice at an organizational level can bring valuable insights and points of reflection for workplaces. Doing so will not only lead to a more contextually-rich consideration of the mutual constitution of ageing and organization, but ensure that we recognize that policies and practices as afforded a different ontological status as one piece or an interactive puzzle that constitutes ageing at work.

\section{References}


Abraham, J. D., and Hansson, R. O. (1995). Successful aging at work: An applied study of selection, optimization, and compensation through impression management. The Journals of Gerontology Series B: Psychological Sciences and Social Sciences, 50(2), 94-103.

Acker, J. (1990). Hierarchies, jobs, bodies: A theory of gendered organizations. Gender \& society, 4(2), 139-158.

Ainsworth, S., and Hardy, C. (2008). The enterprising self: An unsuitable job for an older worker. Organization, 15(3), 389-405.

Alaimo, S. (2010). Bodily natures: Science, environment, and the Material Self. Indiana University Press.

Baltes, P.B., and Baltes, M. M. (1990). Psychological perspectives on successful aging: The model of selective optimization with compensation. In P. B. Baltes and M. M. Baltes (eds.), Successful Aging: Perspectives from the Behavioral Sciences (pp. 1-34). Cambridge: Cambridge University Press.

Barad, K. (2010). Quantum entanglements and hauntological relations of inheritance: Dis/continuities, spacetime enfoldings, and justice-to-come. Derrida Today, 3(2), 240-268.

Benson, J., and Brown, M. (2011). Generations at work: are there differences and do they matter? The International Journal of Human Resource Management, 22(9), 1843-1865.

Bytheway, B. 1995, Ageism, Buckingham, Open University Press. 
Carlile, P.R., Langley, A. and Tsoukas, H. (eds.). (2013). How Matter Matters: Objects, Artifacts, and Materiality in Organization Studies. Oxford: Oxford University Press.

Chan, S. and Huff Stevens, A. (2001). Job Loss and Employment Patterns of Older Workers. Journal of Labor Economics, 19(2), 484-521.

Cole, T.R. (1992). The Journey of Life: A Cultural History of Aging in America. Cambridge: Cambridge University Press.

Dale, K., and Burrell, G. (2014). Being occupied: An embodied re-reading of organizational 'wellness'. Organization, 21(2), 159-177.

De Souza e Silva, A., and J. Frith. (2012). Mobile Interfaces in Public Space: Locational Privacy, Control, and Urban Sociability. London: Routledge

Fineman S. (2011). Organizing Age. New York: Oxford University Press.

Grady, J. (2013). Trade unions and the pension crisis: defending member interests in a neoliberal world. Employee Relations, 35(3), 294-308.

Haber, C. (2004). Anti-aging medicine: the history life extension and history: the continual search for the fountain of youth. The Journals of Gerontology Series A: Biological Sciences and Medical Sciences, 59(6), B515-B522. 
Hirsch, B.T., Macpherson, D.A. and Hardy, M.A. (2000). Occupational age structure and access for older workers. Industrial and Labor Relations Review, 53(3), 401-418.

Ilmarinen, J.E. (2001). Aging workers. Occupational and Environmental Medicine, 58(8), 546-546.

Ingold, T. (2000). The Perception of the Environment: Essays on Livelihood, Dwelling and Skill. Oxon: Routledge.

Irni, S. (2009). Cranky old women? Irritation, resistance and gendering practices in work organizations. Gender, Work \& Organization, 16(6), 667-683.

Katz, S. (2000). Busy bodies: Activity, aging, and the management of everyday life. Journal of Aging Studies, 14(2), 135-152.

Katz, S. and Calasanti, T. (2015) Critical perspectives on successful aging: Does it "appeal more than it illuminates?. The Gerontologist, 55(1), 26-33.

Koch, T. and Webb, C. (1996). The biomedical construction of ageing: implications for nursing care of older people. Journal of Advanced Nursing, 23(5), 954-958.

Lemon, B.W., Bengtson, V.L. and Peterson, J.A. (1972). An exploration of the activity theory of aging: Activity types and life satisfaction among in-movers to a retirement community. Journal of Gerontology, 27(4), 511-523. 
Lorbiecki, A. and Jack, G. (2000). Critical turns in the evolution of diversity management. British Journal of Management, 11(s1), S17-S31.

Loretto W, and White P. (2006). Employers' Attitudes, Practices and Policies Towards Older Workers. Human Resource Management Journal, 16(3), 313-330.

Malul, M. (2009). Older workers' employment in dynamic technology changes. The Journal of Socio-Economics, 38(5), 809-813.

Martin, D. J. and Gillen, L.L. (2013). Revisiting gerontology's scrapbook: From Metchnikoff to the Spectrum Model of Aging. The Gerontologist, Online First 10.1093/geront/gnt073.

McDowell, L. (2011) Redundant Masculinities: Employment Change and White Working Class Youth. Oxford: Blackwell.

McMullin, J., Duerden, A., Comeau, T. and Jovic, E. (2007). Generational affinities and discourses of difference: A case study of highly skilled information technology workers. The British Journal of Sociology, 58(2), 297-316.

Moore, S. (2009). 'No matter what I did I would still end up in the same position' age as a factor defining older women's experience of labour market participation. Work, Employment \& Society, 23(4), 655-671. 
Moulaert, T. and Biggs, S. (2013). International and European policy on work and retirement: Reinventing critical perspectives on active ageing and mature subjectivity. Human Relations, 66(1), 23-43.

Orlikowski, W.J. and Scott, S.V. (2008). Sociomateriality: Challenging the separation of technology, work and organization. The Academy of Management Annals, 2(1), 433-474.

Parikka, J. (2012). New materialism as media theory: Medianatures and dirty matter. Communication and Critical/Cultural Studies, 9(1), 95-100.

Parry E. and Tyson S. (2009) Organizational Reactions to UK Age Discrimination Legislation. Employee Relations, 31(5):471-488.

Popkin S., Morrow S., Di Domenico T. and Howarth H. (2008) Age is more than just a number: implications for an aging workforce in the US transportation sector. Applied Ergonomics 39(5):542-549.

Pritchard, K., and Whiting, C. (2014). Baby boomers and the lost generation: on the discursive construction of generations at work. Organization Studies, 35(11): 1605-1626.

Rhodes, S. R. (1983). Age-related differences in work attitudes and behavior: A review and conceptual analysis. Psychological Bulletin, 93(2), 328.

Riach, K. (2009). Managing 'difference': Understanding age diversity in practice. Human Resource Management Journal, 19(3), 319-335. 
Riach, K., and Cutcher, L. (2014). Built to last: ageing, class and the masculine body in a UK hedge fund. Work, Employment \& Society, 28(5), 771-787.

Riach, K., and Kelly, S. (2013). The need for fresh blood: understanding organizational age inequality through a vampiric lens. Organization, online first 1350508413508999.

Robson, S.M., Hansson, R.O., Abalos, A. and Booth, M. (2006). Successful aging criteria for aging well in the workplace. Journal of Career Development, 33(2), 156-177.

Rowe, J.W. and Kahn, R.L. (1997). Successful aging. The Gerontologist, 37(4), 433-440.

Scott, S.V. and Orlikowski, W.J. (2012). Reconfiguring relations of accountability: Materialization of social media in the travel sector. Accounting, Organizations and Society, 37(1), 26-40.

Spedale, S., Coupland, C. and Tempest, S. (2014). Gendered Ageism and Organizational Routines at Work: The Case of Day-Parting in Television Broadcasting. Organization Studies, $35(11), 1585-1604$

Thomas, R., Hardy, C., Cutcher, L. and Ainsworth, S. (2014). What's age got to do with it? On the critical analysis of age and organizations. Organization Studies, 35(11), 1569-1584. 
Trethewey, A. (2001). Reproducing and resisting the master narrative of decline midlife professional women's experiences of aging. Management Communication Quarterly, 15(2), $183-226$.

Van Dalen, H. P., Henkens, K. and Schippers, J. (2009). Dealing with older workers in Europe: a comparative survey of employers' attitudes and actions. Journal of European Social Policy, 19(1), 47-60.

Walker, A. (1981). Towards a political economy of old age. Ageing and Society, 1(01), 7394.

Walker, A. (2005). Towards an International political economy of ageing. Ageing and Society, 25(06), 815-839.

Weick, K. (1969) The Social Psychology of Organizing. Reading: McGraw-Hill.

Zanoni, P. (2011). Diversity in the lean automobile factory: doing class through gender, disability and age. Organization, 18(1): 105-127. 